\title{
Magnetic targeting as a strategy to enhance therapeutic effects of mesenchymal stromal cells
}

\author{
Luisa H. A. Silva', Fernanda F. Cruz', Marcelo M. Morales², Daniel J. Weiss ${ }^{3}$ and Patricia R. M. Rocco ${ }^{1 *}$
}

\begin{abstract}
Mesenchymal stromal cells (MSCs) have been extensively investigated in the field of regenerative medicine. It is known that the success of MSC-based therapies depends primarily on effective cell delivery to the target site where they will secrete vesicles and soluble factors with immunomodulatory and potentially reparative properties. However, some lesions are located in sites that are difficult to access, such as the heart, spinal cord, and joints. Additionally, low MSC retention at target sites makes cell therapy short-lasting and, therefore, less effective. In this context, the magnetic targeting technique has emerged as a new strategy to aid delivery, increase retention, and enhance the effects of MSCs. This approach uses magnetic nanoparticles to magnetize MSCs and static magnetic fields to guide them in vivo, thus promoting more focused, effective, and lasting retention of MSCs at the target site. In the present review, we discuss the magnetic targeting technique, its principles, and the materials most commonly used; we also discuss its potential for MSC enhancement, and safety concerns that should be addressed before it can be applied in clinical practice.
\end{abstract}

Keywords: Mesenchymal stromal cells, Superparamagnetic nanoparticles, Biocompatibility, Magnetic devices, Magnetic targeting, Cell therapy

\section{Background}

Mesenchymal stromal cells (MSCs) obtained from various sources, including bone marrow, adipose tissue, placental tissue, and others, have been widely investigated in regenerative medicine research [1]. Besides their ability to differentiate into various mesodermal cell lineages, MSCs also have immunomodulatory properties, acting on innate and adaptive immune cells with resulting attenuation of the inflammatory response $[1,2]$ which broadens their potential clinical applications.

These immunomodulatory effects of MSCs are predominantly mediated by secretion of paracrine factors that have anti-inflammatory, anti-apoptotic, antifibrotic, and angiogenic properties [1]. These factors include serum proteins, growth factors, hormones, cytokines, extracellular matrix proteases, lipid mediators, messenger RNAs,

\footnotetext{
* Correspondence: prmrocco@gmail.com

'Laboratory of Pulmonary Investigation, Carlos Chagas Filho Institute of Biophysics, Federal University of Rio de Janeiro, Av. Carlos Chagas Filho, 373, Ilha do Fundão, Rio de Janeiro, RJ 21941-902, Brazil

Full list of author information is available at the end of the article
}

and microRNAs [3]. Additionally, some of these factors may be secreted into extracellular vesicles-cytosolic fragments with spheroid morphology enclosed by a lipid bilayer [3].

Despite the functionality of MSCs, their therapeutic efficacy in experimental models [4] has not been observed in human patients [5]. These results can be explained by two reasons. First, MSCs are not properly activated in human microenvironments and thus fail to exert immunomodulation and secrete repairing factors. Several strategies have been tested to increase MSC potency, such as cultivation of MSCs in hypoxic conditions [6], in the presence of interferon (IFN)- $\gamma$ [7], or with serum extracted from patients with respiratory distress syndrome (ARDS) [8]. The second reason concerns the level of difficulty associated with delivery of MSCs and their engraftment at certain target sites, i.e., few MSCs reach the myocardium, spinal cord, and joints after systemic administration, which is a preferred noninvasive route [9]. However, when MSCs were locally administered, long-lasting retention in sites of injury did not 
occur $[10,11]$. It is known that MSCs are dragged through the bloodstream when administered directly to the heart [11]. Since few cells arrive and engraft at the injury site, fewer repairing factors are secreted, thus slowing recovery.

To optimize MSC delivery and retention, the magnetic targeting (MT) technique has been tested. Initially developed to optimize chemotherapeutic procedures, this technique is based on prior magnetization of MSCs followed by in vivo targeting with the aid of magnetic fields. MT would thus enable a larger portion of inoculated cells to reach the site of injury, providing greater and longer lasting release of mediators without the need to increase the cell volume administered [11].

Based on the foregoing, this review aims to discuss the MT technique, explaining its principles and the materials commonly used; we also discuss the potential of MT for enhancement of MSC properties, and safety concerns that should be addressed before MT can be applied in clinical practice.

\section{The magnetic targeting technique}

Briefly, MT of MSCs involves three steps: 1) isolation, growth, and maintenance of MSCs in culture; 2) magnetization of MSCs; and 3) in vivo guidance of magnetized MSCs by static magnetic fields [12]. A schematic diagram is provided in Fig. 1.
MSC magnetization with superparamagnetic nanoparticles Magnetization is achieved by diluting magnetic nanoparticles (MNPs) in cell culture medium and cocultivating them with MSCs. The MSCs internalize the nanoparticles by passive diffusion or endocytosis, generally over a few hours [13]. Some of the materials commonly used for the production of these MNPs-iron, nickel, and cobalt-may be toxic to the cells themselves or for in vivo application [14]. However, among these, the iron oxides magnetite $\left(\mathrm{Fe}_{3} \mathrm{O}_{4}\right)$ and maghemite $\left(\gamma-\mathrm{Fe}_{2} \mathrm{O}_{3}\right)$ are considered safer components [15]. Furthermore, maghemite MNPs cause less damage to receptor cells compared to magnetite by having iron in an oxidized state $\left(\mathrm{Fe}^{3+}\right)[16]$.

MNPs smaller than $30 \mathrm{~nm}$ are superparamagnetic, i.e., their magnetization only occurs in the presence of an external magnetic field [16]. This is a desirable property for biological applications. Thus, these small superparamagnetic nanoparticles (SPIONs) are essential materials for potential clinical applications of MT-augmented MSC-based cell therapies. In addition, they can also be used as contrast agents for MSC labeling and tracking in vivo due to the strong signal they generate in magnetic resonance imaging (MRI) [16].

Importantly, SPION aggregation in cell culture media can hinder MSC magnetization since their availability for contact with the cells decreases; furthermore, when SPIONs agglomerate, the size of the resulting cluster is similar to or larger than MSCs, thus resulting in a

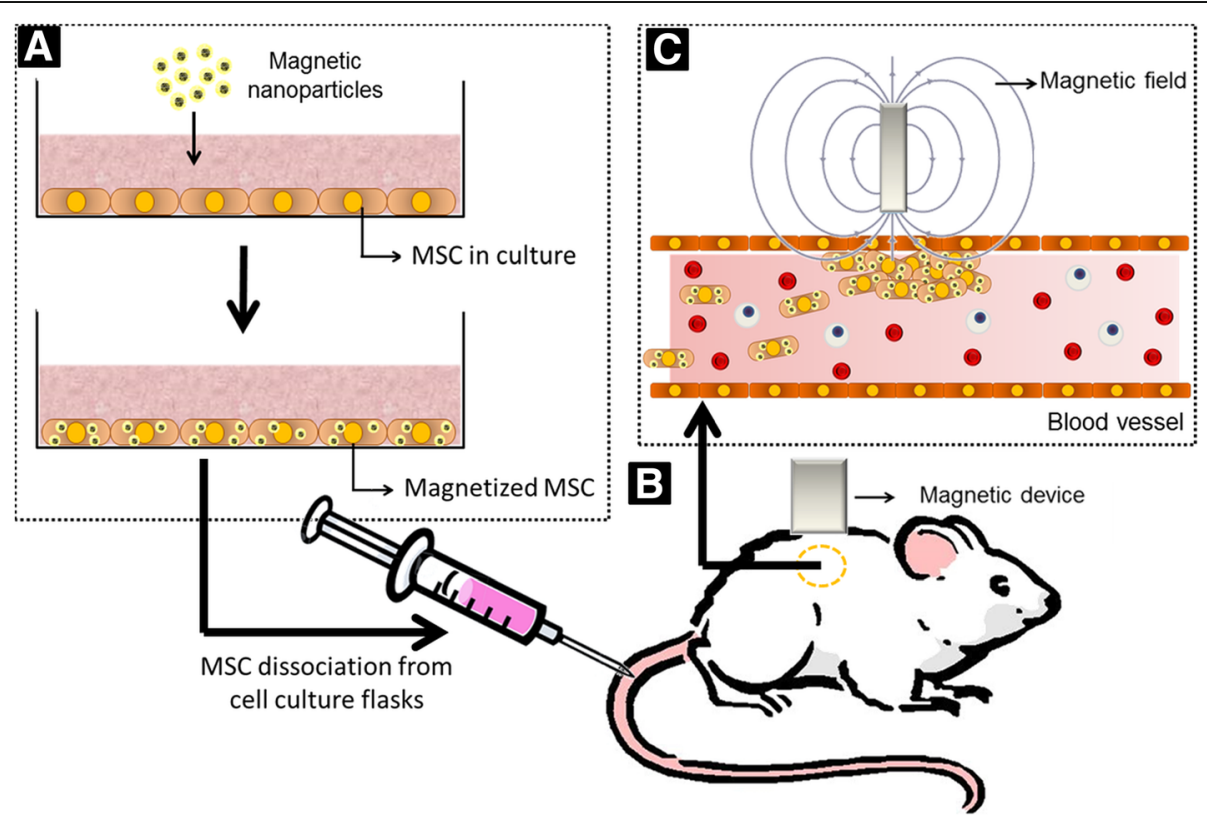

Fig. 1 Schematic diagram of magnetic targeting of mesenchymal stromal cells. a In the first step, mesenchymal stromal cells (MSCS) are expanded in culture and magnetized with magnetic nanoparticles. $\mathbf{b}$ Once magnetized, the cells are injected into animals which are exposed to static magnetic fields generated by magnetic devices. c Magnetized MSCs are better retained in regions where the static magnetic field is present 
physical restriction for MSC uptake [17]. To minimize such clumping and to promote solubility in aqueous media and in physiological conditions, SPIONs are coated with biocompatible substances (dextran, carboxidextran, polyethylene glycol, polystyrene, silica, etc.) [15]. Importantly, the charge of the SPION coating agent influences their uptake by MSCs: cationic agents interact electrostatically with the negative cell membrane and promote adsorptive endocytosis. In contrast, dextran-coated SPIONs, which are neutral, are not well captured [18]. However, there are additional strategies to optimize the uptake of neutral SPIONs which include physical (electroporation, microinjection, and magnetofection) and biochemical methods (conjugation of antibodies, peptides, or aptamers) [18].

To date, eight different MNPs have been tested for MT of MSCs (Table 1). Most of these are commercially available and/or US Food and Drug Administration (FDA) approved [12]. The commercially available SPION ferucarbotran (Resovist ${ }^{\circ}$, Bayer Schering Pharma AG), a carboxydextran-coated SPION with crystalline diameter ranging from 45 to $60 \mathrm{~nm}$, has been most investigated.

\section{Static magnetic fields}

Once magnetized, MSCs can be guided in vivo by being attracted by external static magnetic fields (SMFs). The intensity of these SMFs is categorized, according to their power induction, as weak $(<0.001$ Tesla $(\mathrm{T}))$, moderate (0.001-1 T), strong $(1-5 \mathrm{~T})$, and ultra-strong $(>5 \mathrm{~T})$. Moderate SMFs are those most exploited for clinical MT purposes [19].
Two types of magnetic devices have been used to generate SMFs for MT of MSCs: permanent magnets and electromagnets [12]. Permanent magnets are materials that produce a persistent magnetic field independently of any external magnetic fields. In the context of MT, permanent rare-earth magnets (neodymium-iron-boron) are usually used to generate SMFs since they are portable, reach higher field strengths compared to electromagnets of similar size, and do not require a power supply or cooling system [12]. These magnets can be placed externally above the target site [20] or internally under the skin [21, 22]. However, most studies opt to place magnets externally to avoid the risk of implantation surgery [12, 22] (Table 1). It is also important to mention that the SMFs provided by permanent magnets decay over distance and, therefore, do not reach the inner most parts of the body. To address this issue, placement of multiple permanent magnets in different positions to extend SMF reach has been used, enabling cell delivery to regions such as the spinal cord [20].

Unlike a permanent magnet, an electromagnet only exhibits magnetism when an electric current is flowing through it. SMFs generated by electromagnets have been widely used for MT therapy targeting muscles and joints, being placed externally on the target region, promoting focused MSC retention [10, 23]. Moreover, electromagnets can produce much higher field strengths than permanent magnets; however, they require a constant power supply and must be supercooled to maintain low resistance and prevent overheating [12].

Computational simulations have shown the potential of MRI systems to magnetically guide stem cells [12], an

Table 1 Application of magnetic targeting techniques in pre-clinical studies

\begin{tabular}{|c|c|c|c|c|c|c|}
\hline Target & MSC donor & MSC recipient & Nanoparticle & Magnetic device & Magnetic device position & Reference \\
\hline \multirow[t]{2}{*}{ Knee joint (cartilage) } & Human & Pigs and rabbits & Feridex (Tanabe Seiyaku) & Electromagnet & External & [10] \\
\hline & Rabbit & Rabbits & Ferucarbotran/Resovist ${ }^{\circledR}$ & Permanent magnet & External & [24] \\
\hline Meniscus & Rabbit & Rabbit & Ferucarbotran/Resovist ${ }^{\oplus}$ & Permanent magnet & External & [25] \\
\hline Skeletal muscle & Human & Rats & Risovist ${ }^{\oplus}$ & Electromagnet & External & [23] \\
\hline Bones & Rat & Rats & Ferucarbotran/Resovist ${ }^{\oplus}$ & Permanent magnet & External & [26] \\
\hline \multirow[t]{2}{*}{ Spinal cord } & Rat & Rats & Poly-L-lysine-coated SPIONs & Permanent magnet & Implanted & [21] \\
\hline & Not reported & Rats & Not reported & Permanent magnet & External & [20] \\
\hline Retina & Rat & Rats & FluidMAG-D ${ }^{\circledR}$ & Permanent magnet & Implanted & [27] \\
\hline Arteries & Rabbit & Rabbits & FluidMAG-D ${ }^{\oplus}$ & Permanent magnet & External & [29] \\
\hline \multirow[t]{3}{*}{ Heart } & Rat & Rats & Ferucarbotran/Resovist ${ }^{\oplus}$ & Permanent magnet & External & [49] \\
\hline & Pig & Pigs & $\begin{array}{l}\text { Gadolinium nanotubes } \\
\text { and Molday ION(- })^{\odot}\end{array}$ & Permanent magnet & Implanted & [22] \\
\hline & Rat & Rats & Ferucarbotran/Resovist ${ }^{\oplus}$ & Permanent magnet & External & [11] \\
\hline Lung & Human & Mouse & $\begin{array}{l}\text { DMSA-coated maghemite } \\
\text { nanoparticles }\end{array}$ & Permanent magnet & External & [33] \\
\hline
\end{tabular}


interesting possibility that would allow magnetically targeted cells to home to specific portions of the body while simultaneously providing information regarding in vivo MSC localization. Therefore, ideally, a SPION should be chosen that provides localization information on MRI while making receptor MSCs magnetically responsive.

\section{Benefits of magnetic targeting in experimental studies}

MT of MSCs has been trialed most often for the repair of articular cartilages which have limited healing potential $[10,24]$ (Table 1). Intra-articular MSC injections into cartilage defect regions resulted in poor engraftment, suggesting the need for inoculation of additional cell volumes. However, administration of larger MSC amounts can generate loose bodies of fibrotic tissue, affecting joint biomechanics [10]. Therefore, for safe treatment, appropriate numbers of MSCs must be transplanted efficiently into the joint.

SMFs from extracorporeal permanent magnets placed next to the knee joint were found to provide better engraftment of SPION-labeled MSCs after their injection into cartilage degeneration sites. Additionally, MT avoids MSC migration to any major organs and formation of loose bodies [10, 24].

Likewise, MT with external permanent magnets/electromagnets has been shown to enhance MSC engraftment in other parts of the musculoskeletal system, such as fibrocartilages (meniscus) [25], muscles [23], and bones [26] (Table 1). These areas also have limited regenerative capacity and may be poorly accessible by systemic or local MSC inoculation.

MT has also been tested in models of central nervous system lesions. In rat models of spinal cord injury, SPION-labeled MSCs were administered intrathecally and guided by implanted [21] or external [20] permanent magnets to the injured sites (Table 1). In one of these studies, histological analysis showed significantly higher MSC counts at the lesion site with the aid of implanted magnets $(9595 \pm 2231$ cells $)$ than in control groups (3538 \pm 625 cells) $12 \mathrm{~h}$ after cell administration [21]. Importantly, MSC retention was uniform and concentrated in regions close to the injury sites [20, 21]. However, whether this enhancement led to clinical improvement was not assessed.

In one study, intravenously administered MSCs were successfully guided into small dystrophic areas of the retina with the aid of implanted magnets; MSC counts over the retinal surface were 10-fold greater than in animals without magnets [27]. Therefore, MT of MSCs resulted in higher retinal concentrations of anti-inflammatory molecules, such as interleukin-10 and hepatocyte growth factor, providing evidence of a significant therapeutic benefit in the dystrophic retina model [27].

In cardiovascular diseases, MSCs retention is less than $10 \%$ after $24 \mathrm{~h}$ and long-term engraftment is even more infrequent since these cells are usually delivered by the intravascular route and, thus, are subject to a washout effect caused by heart contractions and venous drainage [28]. Nevertheless, MT may improve cardiac retention of MSCs through cell magnetization and placement of magnets either on the heart or injured vessels [28] (Table 1).

The potential of MSC MT to reduce the risk of restenosis and reocclusion of treated vessels after angioplasty has been assessed [29]. In a femoral artery injury model, permanent magnets were placed externally on the leg at the site of injury and remained in place for $24 \mathrm{~h}$ while cells were injected directly into the diseased artery. This technique led to a sixfold increase in MSC retention, avoiding the washout effect, and a reduction in restenosis 3 weeks after cell injection [29].

Magnetically targeted MSCs were also found to provide enhanced therapeutic benefit in models of myocardial infarction [11, 22]. In one report, transplanted MSC counts in the ventricular wall were approximately 3.04-times greater than those measured in control groups $(25.8 \pm 4.7$ versus $8.5 \pm 2.0$ ). As a consequence, left ventricular remodeling was attenuated and cardiac function was ameliorated [11]. In these studies, the cells were injected intravenously or locally into the epicardium, while permanent magnets were placed internally, close to the target region, without impairing cardiac function [11, 22].

Some mechanisms may explain why MT potentiated the therapeutic effects of MSCs in these studies. First, MT enhances MSC retention in injury sites as a consequence of magnetic interactions between magnetized cells and SMFs and MSC gene expression changes [13]. One hour after SMF exposure, in vitro, magnetized MSCs presented increased expression of integrins (alpha 2 , alpha 6, and beta 3), adhesion molecules (intercellular adhesion molecule- 2 and platelet endothelial cell adhesion molecule), and other proteins, such as CD93 (involved in innate immunity, inflammation, and adhesion to endothelium) and cadherin 7 (involved in cell adhesion, dispersion, and migration) [30,31]. These changes may contribute to increased adherence and engraftment to target sites in vivo, which is particularly interesting for cardiac and orthopedic applications. Therefore, higher MSC retention would arguably result in greater release of soluble factors and restorative action. Secondly, SMFs increase secretion of membrane-derived extracellular vesicles by MSCs in vitro, as well as induce changes in their content [32]. The vesicles derived from MSCs exposed to SMFs are richer in some specific growth factors, including bone morphogenetic protein 2 
(BMP-2) and vascular endothelial growth factor (VEGF) [32]. These factors may all play therapeutic roles in cardiovascular and musculoskeletal disorders.

Although magnetically targeted MSCs have shown positive effects in vivo, the MT technique has yet to be extensively investigated in other experimental models, such as lung and liver diseases (Table 1). In a recent report, MT was found to enhance MSC retention in murine lungs [33]. For MT, permanent magnets were attached to the dorsal region, above the thorax, and SPION-labeled MSCs were immediately administered via the jugular vein [33]. The findings of this experiment suggest that MT has potential to guide MSCs to injured areas in lungs.

There are no reports on the use of MT in cell therapy for renal diseases. This may be explained by the ease of access of MSCs to the kidneys after systemic administration due to capillary trapping, which eliminates the need for techniques to increase engraftment [9].

\section{Concerns}

Even though MT has been shown to potentiate the therapeutic effects of MSCs in different experimental models, some safety concerns need to be addressed prior to conducting clinical trials with this technique. These include issues of biocompatibility between MSCs and SPIONs, the influence of SMFs on MSCs, and in vivo adverse effects.

\section{SPION-MSC interactions}

When excess ferric or ferrous ions accumulate in the cytoplasm in noncomplexed form they catalyze biomolecular oxidation reactions, increasing the rate of freeradical generation [34]. These radicals can irreversibly modify amino acids, denature or aggregate proteins, oxidize nucleotides, and promote lipid peroxidation [34]. Nevertheless, none of the SPIONs used in MSC MT studies have been shown to exert toxic effects on recipient cells [33, 35-37].

SPIONs are biocompatible with MSCs due to their surface chemical modifications. Capping agents are used not only to ensure SPION stability in physiological media, but also to keep the iron core isolated from biomolecules, enhancing the safety of this material for biological applications [38]. SPION toxicity, therefore, is dependent on coating agent stability in culture medium or after cell uptake; if the nanoparticle coating is easily degraded, the metal core is then free to react with biomolecules. Importantly, cationic or anionic capping agents, such as dimercaptosuccinic acid (DMSA), are more difficult to remove from the nanostructure compared to neutral substances, such as dextran or albumin [38].
Another reason for SPION biocompatibility is that these nanoparticles may have an activity similar to that of natural catalases, which, importantly, depends on the acidity of the surrounding cellular environment [39].

Looking beyond toxicological issues, the potential impacts of SPIONs on the fundamental biological features of MSCs, such as proliferation, immunomodulation, and differentiation, are less well understood. Ferucarbotran has been shown to stimulate in vitro MSC proliferation [40], exert an inhibitory effect on osteogenesis [41] and chondrogenesis [42], and to reduce cell migration potential and colony-forming ability [35]. It is important to note that these studies used different SPION concentrations and times of exposure, thus precluding comparison of dose-response and time-response patterns.

Furthermore, infusion of MSCs labeled with a SPION for MRI tracking purposes in a rat model of multiple sclerosis led to aggravation of symptoms, whereas unlabeled MSCs ameliorated symptoms [43]. One hypothesis is that SPIONs increased free-radical release, intensifying inflammatory responses and accelerating disease progression [43]. Given these observations, it is important to carry out biocompatibility tests prior to in vivo experiments and clinical trials so as to mitigate adverse effects related to SPIONMSC interactions.

\section{Effects of SMFs on MSC viability and function}

Recently, several studies have been conducted to assess how SMFs influence biological systems [44]. It was found that SMFs can affect the rotation of cell membrane phospholipids by virtue of their diamagnetic properties. This leads to changes in cell shape, cytoskeletal rearrangement, and alterations in ion channel function. Through these ion channel changes, SMFs can decrease intracellular calcium ion concentrations, which may explain some of their observed effects, including modulation of apoptosis, proliferation, and cell viability [45]. Importantly, the type and extent of modifications in cell shape and function depends on cell type and age, field strength, and time of exposure [44].

These facts raise concerns about the potential influences of SMFs on the biological functions of MSCs and on patients as a whole. To date, reports of SMF use with MSCs have demonstrated that moderate SMFs can have divergent effects (enhancing or inhibiting) on MSC viability [19, 45], proliferation [45-47], differentiation capacity [19, 31, 47, 48], colony formation [31], and extracellular vesicle secretion $[19,46]$ (summarized in Table 2 and Fig. 2). In addition, the risk of vascular embolisms must be considered [49]. In an ischemic rat model subjected to intracavitary SPION-labeled MSC 
Table 2 Effects of SPIONs and static magnetic fields on mesenchymal stromal cell properties

\begin{tabular}{|c|c|c|c|c|c|c|}
\hline MSC origin & Nanoparticle & Magnetic device & $\begin{array}{l}\text { SMF } \\
\text { strength }(\mathrm{mT})\end{array}$ & $\begin{array}{l}\text { Time of } \\
\text { exposure }\end{array}$ & $\begin{array}{l}\text { Effects of SMFs on MSC } \\
\text { (compared to control groups) }\end{array}$ & Reference \\
\hline Human bone marrow & $\begin{array}{l}\text { Ferucarbotran/Resovist }{ }^{\oplus} \\
(60 \mu \mathrm{g} / \mathrm{ml})\end{array}$ & Permanent magnet & 600 & $\begin{array}{l}24 \text { hours and } \\
12 \text { days }\end{array}$ & $\begin{array}{l}\text { Reduction of colony-forming units, } \\
\text { increased adipogenesis, and } \\
\text { osteogenesis inhibition }\end{array}$ & {$[31]$} \\
\hline Human bone marrow & $\begin{array}{l}\text { Feridex } \\
\text { (Tanabe Seiyaku) }\end{array}$ & Electromagnet & 600 & 1 hour & $\begin{array}{l}\text { Increased expression of integrins } \\
\text { and adhesion proteins }\end{array}$ & [30] \\
\hline Murine bone marrow & None & Electromagnet & 4,7 , and 15 & 1 to 4 days & $\begin{array}{l}\text { Reduction of MSC viability and } \\
\text { proliferation rates }\end{array}$ & {$[45]$} \\
\hline $\begin{array}{l}\text { Canine and equine } \\
\text { adipose tissue }\end{array}$ & None & Permanent magnet & 500 & 1 to 7 days & $\begin{array}{l}\text { Increased MSC proliferation rates in } \\
\text { both species; increased secretion of } \\
\text { extracellular vesicles by equine MSCS }\end{array}$ & {$[46]$} \\
\hline Human bone marrow & None & Permanent magnet & 400 & 14 days & Increased chondrogenesis & [48] \\
\hline Equine adipose tissue & None & Permanent magnet & 500 & 1 to 7 days & $\begin{array}{l}\text { Ultrastructural changes; increased } \\
\text { proliferation rate, colony-forming } \\
\text { units, and secretion of extracellular } \\
\text { vesicles; changes in vesicle content. }\end{array}$ & {$[32]$} \\
\hline Human bone marrow & None & Permanent magnet & 3,15, and 50 & 1 to 9 days & $\begin{array}{l}\text { Increased MSC proliferation rates; } \\
\text { osteogenesis stimulation. }\end{array}$ & {$[47]$} \\
\hline Murine adipose tissue & Feridex (Berlex) & Permanent magnet & 500 & 7 days & $\begin{array}{l}\text { Reduction of MSC viability, } \\
\text { proliferation rates, angiogenic } \\
\text { cytokine release, osteogenesis and } \\
\text { adipogenesis; phenotype shift. }\end{array}$ & [18] \\
\hline
\end{tabular}

MSC mesenchymal stromal cell, SMF static magnetic field, SPION superparamagnetic iron oxide nanoparticle

injection, high SMF intensities induced cell accumulation in the vessel lumen $[49,50]$. In this study, a permanent magnet was placed next to the injured myocardium for only $20 \mathrm{~min}(10 \mathrm{~min}$ after and $10 \mathrm{~min}$ before cell injection).

Finally, it must be noted that these studies used MSCs isolated from different tissues, were conducted in various species, and applied different SMF intensities during various exposure times. Thus, comparisons are extremely limited. Nevertheless, the adverse effects of SMFs on MSCs can be mitigated by reducing exposure time [28]. For example, MSCs labeled with SPIONs and subjected to a moderate SMF $(0.6 \mathrm{~T})$ for $1 \mathrm{~h}$ did not exhibit changes in proliferation rate over 3 weeks, indicating viability [30]. Any potential complications of SMF and SPION effects on MSCs in vitro and in vivo must be thoroughly investigated and overcome before clinical use.

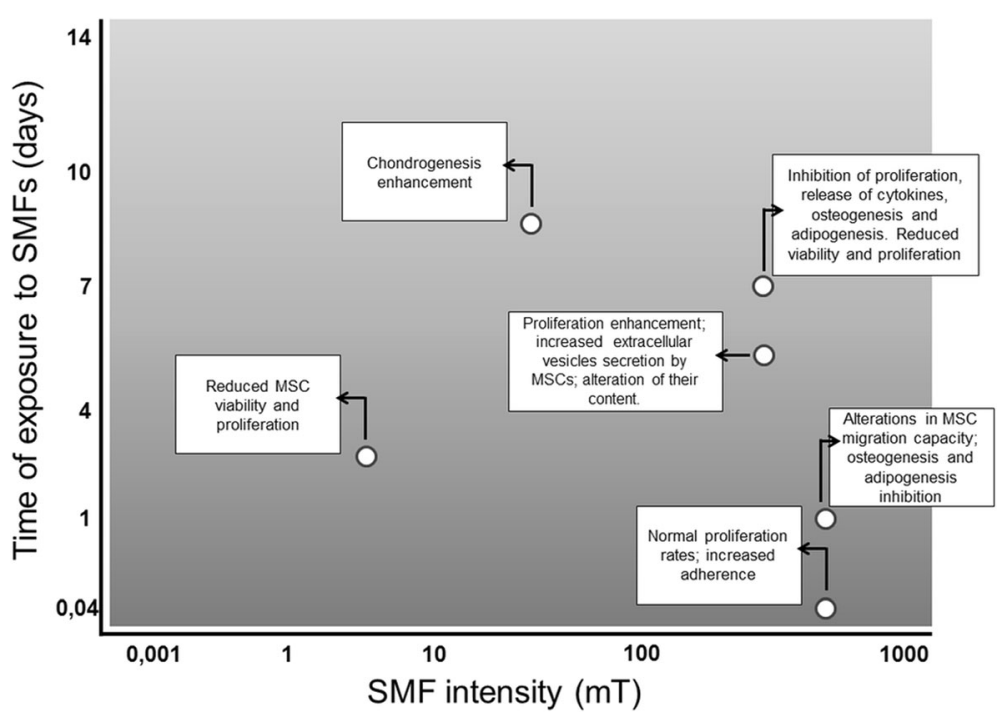

Fig. 2 Effects of static magnetic fields (SMFs) on mesenchymal stromal cells (MSCS). The combination of different field intensities ( $x$-axis) and different exposure times (y-axis) promotes varying effects on these cells 


\section{Conclusions}

The intensity and duration of the beneficial effects of clinical MSC administration may be enhanced by MT, due to the efficacy of this technique in guiding cells to disease foci, improving their retention and engraftment, and, possibly, enhancing immunomodulatory properties. Therefore, MT is a potentially exciting approach for improving the efficacy of MSC-based cell therapies. However, there is still much to learn about the optimal use of MT with MSCs and minimizing or eliminating any potential adverse effects.

\section{Abbreviations \\ MNP: Magnetic nanoparticle; MRI: Magnetic resonance imaging; MSC: Mesenchymal stromal cell; MT: Magnetic targeting; SMF: Static magnetic field; SPION: Superparamagnetic iron oxide nanoparticle}

\section{Acknowledgements}

The authors would like to express their gratitude Mrs. Moira Elizabeth Schottler and Mr. Filippe Vasconcellos for their assistance in editing the article.

\section{Funding}

This study was supported by the Brazilian Council for Scientific and Technological Development (CNPq), the Rio de Janeiro State Research Foundation (FAPERJ), the Coordination for the Improvement of Higher Education Personnel (CAPES), and the Department of Science and Technology_Brazilian Ministry of Health (DECIT/MS).

\section{Availability of data and materials}

Not applicable.

\section{Authors' contributions}

LHAS, FFC, MMM, DJW, and PRMR are responsible for the concept of the review. LHAS and PRMR were responsible for writing the first draft of the manuscript. DJW, MMM, and PRMR were responsible for critical review of the manuscript. All authors read and approved the final manuscript.

\section{Competing interests}

The authors declare that they have no competing interests.

\section{Consent for publication}

Not applicable.

\section{Ethics approval and consent to participate}

Not applicable.

\section{Author details}

${ }^{1}$ Laboratory of Pulmonary Investigation, Carlos Chagas Filho Institute of Biophysics, Federal University of Rio de Janeiro, Av. Carlos Chagas Filho, 373, Ilha do Fundão, Rio de Janeiro, RJ 21941-902, Brazil. 'Laboratory of Cellular and Molecular Physiology, Carlos Chagas Filho Institute of Biophysics, Federal University of Rio de Janeiro, Av. Carlos Chagas Filho, 373, Ilha do Fundão, Rio de Janeiro, RJ 21941-902, Brazil. 'Department of Medicine, Vermont Lung Center, College of Medicine, University of Vermont, 89 Beaumont Ave. Given, Burlington, VT 05405, USA.

Published online: 09 March 2017

\section{References}

1. Spees JL, Lee RH, Gregory CA. Mechanisms of mesenchymal stem/stromal cell function. Stem Cell Res Ther. 2016:7:125.

2. Cruz FF, Weiss DJ, Rocco PRM. Prospects and progress in cell therapy for acute respiratory distress syndrome. Expert Opin Biol Ther. 2016;16:1353-60.

3. Abreu SC, Weiss DJ, Rocco PRM. Extracellular vesicles derived from mesenchymal stromal cells: a therapeutic option in respiratory diseases? Stem Cell Res Ther. 2016;7:53.

4. Antunes MA, Abreu SC, Cruz FF, Teixeira AC, Lopes-Pacheco M, Bandeira E, Olsen PC, Diaz BL, Takyia CM, Freitas IP, Rocha NN, Capelozzi VL, Xisto DG,
Weiss DJ, Morales MM, Rocco PR. Effects of different mesenchymal stromal cell sources and delivery routes in experimental emphysema. Respir Res. 2014;15:118

5. Weiss DJ, Casaburi R, Flannery R, LeRoux-Williams M, Tashkin DP. A placebocontrolled, randomized trial of mesenchymal stem cells in COPD. Chest. 2013;143:1590-8.

6. Rosová I, Dao M, Capoccia B, Link D, Nolta JA. Hypoxic preconditioning results in increased motility and improved therapeutic potential of human mesenchymal stem cells. Stem Cells. 2008;26:2173-82.

7. Polchert D, Sobinsky J, Douglas G, Kidd M, Moadsiri A, Reina E, Genrich K, Mehrotra S, Setty S, Smith B, Bartholomew A. IFN-gamma activation of mesenchymal stem cells for treatment and prevention of graft versus host disease. Eur J Immunol. 2008:38:1745-55.

8. Bustos ML, Huleihel L, Meyer EM, Donnenberg AD, Donnenberg VS, Sciurba JD, Mroz L, McVerry BJ, Ellis BM, Kaminski N, Rojas M. Activation of human mesenchymal stem cells impacts their therapeutic abilities in lung injury by increasing interleukin (IL)-10 and IL-1RN levels. Stem Cells Transl Med. 2013;2:884-95.

9. Ankrum J, Karp JM. Mesenchymal stem cell therapy: two steps forward, one step back. Trends Mol Med. 2010;16:203-9.

10. Kobayashi T, Ochi M, Yanada S, Ishikawa M, Adachi N, Deie M, Arihiro K. A novel cell delivery system using magnetically labeled mesenchymal stem cells and an external magnetic device for clinical cartilage repair. Arthroscopy. 2008;24:69-76.

11. Huang Z, Shen Y, Sun A, Huang G, Zhu H, Huang B, Xu J, Song Y, Pei N, Ma J, Yang X, Zou Y, Qian J, Ge J. Magnetic targeting enhances retrograde cell retention in a rat model of myocardial infarction. Stem Cell Res Ther. 2013:4:149.

12. Connell JJ, Patrick PS, Yu Y, Lythgoe MF, Kalber TL. Advanced cell therapies: targeting, tracking and actuation of cells with magnetic particles. Regen Med. 2015;10:757-72.

13. Cores J, Caranasos TG, Cheng K. Magnetically targeted stem cell delivery for regenerative medicine. J Funct Biomater. 2015;6:526-46.

14. Soenen SJH, De Cuyper M. How to assess cytotoxicity of (iron oxide-based) nanoparticles: a technical note using cationic magnetoliposomes. Contrast Media Mol Imaging. 2011:6:153-64.

15. Cromer Berman SM, Walczak P, Bulte JWM. Tracking stem cells using magnetic nanoparticles. Wiley Interdiscip Rev Nanomed Nanobiotechnol. 2011;3:343-55.

16. Taboada E, Rodriguez E, Roig A, Oró J, Roch A, Muller RN. Relaxometric and magnetic characterization of ultrasmall iron oxide nanoparticles with high magnetization. Evaluation as potential T1 magnetic resonance imaging contrast agents for molecular imaging. Langmuir. 2007:23:4583-8

17. Díaz B, Sánchez-Espinel C, Arruebo M, Faro J, de Miguel E, Magadán S, Yagüe C, Fernández-Pacheco R, Ibarra MR, Santamaría J, González-Fernández A. Assessing methods for blood cell cytotoxic responses to inorganic nanoparticles and nanoparticle aggregates. Small. 2008;4:2025-34.

18. Barrow M, Taylor A, Murray P, Rosseinsky MJ, Adams DJ. Design considerations for the synthesis of polymer coated iron oxide nanoparticles for stem cell labelling and tracking using MRI. Chem Soc Rev. 2015;44:6733-48.

19. Wang J, Xiang B, Deng J, Freed DH, Arora RC, Tian G. Inhibition of viability, proliferation, cytokines secretion, surface antigen expression, and adipogenic and osteogenic differentiation of adipose-derived stem cells by seven-day exposure to 0.5 T static magnetic fields. Stem Cells Int 2016:2016:7168175.

20. Tukmachev D, Lunov O, Zablotskii V, Dejneka A, Babic M, Syková E, Kubinová Š. An effective strategy of magnetic stem cell delivery for spinal cord injury therapy. Nanoscale. 2015;7:3954-8.

21. Vaněček V, Zablotskii V, Forostyak S, Rǔžička J, Herynek V, Babič M, Jendelová P, Kubinová S, Dejneka A, Syková E. Highly efficient magnetic targeting of mesenchymal stem cells in spinal cord injury. Int J Nanomedicine. 2012;7:3719-30.

22. Tran LA, Hernández-Rivera M, Berlin AN, Zheng Y, Sampaio L, Bové C, Da M, Cabreira-Hansen G, Willerson JT, Perin EC, Wilson LJ. The use of gadoliniumcarbon nanostructures to magnetically enhance stem cell retention for cellular cardiomyoplasty. Biomaterials. 2014:35:720-6.

23. Oshima S, Kamei N, Nakasa T, Yasunaga Y, Ochi M. Enhancement of muscle repair using human mesenchymal stem cells with a magnetic targeting system in a subchronic muscle injury model. J Orthop Sci. 2014;19:478-88. 
24. Mahmoud EE, Kamei G, Harada Y, Shimizu R, Kamei N, Adachi N, Misk NA, Ochi M. Cell magnetic targeting system for repair of severe chronic osteochondral defect in a rabbit model. Cell Transplant. 2016;25:1073-83.

25. Qi Y, Yang Z, Ding Q, Zhao T, Huang Z, Feng G. Targeted transplantation of iron oxide-labeled, adipose-derived mesenchymal stem cells in promoting meniscus regeneration following a rabbit massive meniscal defect. Exp Ther Med. 2016;11:458-66.

26. Kodama A, Kamei N, Kamei G, Kongcharoensombat W, Ohkawa S, Nakabayashi A, Ochi M. In vivo bioluminescence imaging of transplanted bone marrow mesenchymal stromal cells using a magnetic delivery system in a rat fracture model. J Bone Joint Surg Br. 2012;94:998-1006.

27. Yanai A, Häfeli UO, Metcalfe AL, Soema P, Addo L, Gregory-Evans CY, Po K, Shan X, Moritz OL, Gregory-Evans K. Focused magnetic stem cell targeting to the retina using superparamagnetic iron oxide nanoparticles. Cell Transplant. 2012;21:1137-48.

28. Kyrtatos PG, Lehtolainen P, Junemann-Ramirez M, Garcia-Prieto A, Price AN, Martin JF, Gadian DG, Pankhurst QA, Lythgoe MF. Magnetic tagging increases delivery of circulating progenitors in vascular injury. JACC Cardiovasc Interv. 2009;2:794-802.

29. Riegler J, Liew A, Hynes SO, Ortega D, O'Brien T, Day RM, Richards T, Sharif F, Pankhurst QA, Lythgoe MF. Superparamagnetic iron oxide nanoparticle targeting of MSCs in vascular injury. Biomaterials. 2013;34:1987-94.

30. Nakamae T, Adachi N, Kobayashi T, Nagata Y, Nakasa T, Tanaka N, Ochi M. The effect of an external magnetic force on cell adhesion and proliferation of magnetically labeled mesenchymal stem cells. Sport Med Arthrosc Rehabil Ther Technol. 2010;2:5.

31. Schäfer R, Bantleon R, Kehlbach R, Siegel G, Wiskirchen J, Wolburg H, Kluba $T$, Eibofner $F$, Northoff $H$, Claussen CD, Schlemmer H-P. Functional investigations on human mesenchymal stem cells exposed to magnetic fields and labeled with clinically approved iron nanoparticles. BMC Cell Biol. 2010;11:22.

32. Marędziak M, Marycz K, Lewandowski D, Siudzińska A, Śmieszek A. Static magnetic field enhances synthesis and secretion of membrane-derived microvesicles (MVs) rich in VEGF and BMP-2 in equine adipose-derived stromal cells (EqASCs): a new approach in veterinary regenerative medicine. Vitr Cell Dev Biol Anim. 2015;51:230-40.

33. Silva LHA, da Silva JR, Ferreira GA, Silva RC, Lima ECD, Azevedo RB, Oliveira DM. Labeling mesenchymal cells with DMSA-coated gold and iron oxide nanoparticles: assessment of biocompatibility and potential applications. J Nanobiotechnol. 2016;14:59.

34. Stohs SJ, Bagchi D. Oxidative mechanisms in the toxicity of metal ions. Free Radic Biol Med. 1995;18:321-36.

35. Schäfer R, Kehlbach R, Müller M, Bantleon R, Kluba T, Ayturan M, Siegel G, Wolburg H, Northoff H, Dietz K, Claussen CD, Wiskirchen J. Labeling of human mesenchymal stromal cells with superparamagnetic iron oxide leads to a decrease in migration capacity and colony formation ability. Cytotherapy. 2009;11:68-78.

36. Wang $Y$, Wang L, Che Y, Li Z, Kong D. Preparation and evaluation of magnetic nanoparticles for cell labeling. J Nanosci Nanotechnol. 2011;11:3749-56.

37. Sun J-H, Zhang Y-L, Qian S-P, Yu X-B, Xie H-Y, Zhou L, Zheng S-S. Assessment of biological characteristics of mesenchymal stem cells labeled with superparamagnetic iron oxide particles in vitro. Mol Med Rep. 2012;5:317-20

38. Li J, Chang X, Chen X, Gu Z, Zhao F, Chai Z, Zhao Y. Toxicity of inorganic nanomaterials in biomedical imaging. Biotechnol Adv. 2014;32(4):727-43.

39. Chen Z, Yin J, Zhou Y, Zhang Y, Song L, Song M, Hu S, Gu N, Al CET. Dual enzyme-like activities of iron oxide nanoparticles and their implication for diminishing cytotoxicity. ACS Nano. 2012;6:4001-12.

40. Huang D-M, Hsiao J-K, Chen Y-C, Chien L-Y, Yao M, Chen Y-K, Ko B-S, Hsu S-C, Tai L-A, Cheng H-Y, Wang S-W, Yang C-S, Chen Y-C. The promotion of human mesenchymal stem cell proliferation by superparamagnetic iron oxide nanoparticles. Biomaterials. 2009;30:3645-51.

41. Chen Y-C, Hsiao J-K, Liu H-M, Lai I-Y, Yao M, Hsu S-C, Ko B-S, Chen Y-C, Yang C-S, Huang D-M. The inhibitory effect of superparamagnetic iron oxide nanoparticle (Ferucarbotran) on osteogenic differentiation and its signaling mechanism in human mesenchymal stem cells. Toxicol Appl Pharmacol. 2010;245:272-9.
42. Henning TD, Sutton EJ, Kim A, Golovko D, Horvai A, Ackerman L, Sennino B, McDonald D, Lotz J, Daldrup-Link HE. The influence of ferucarbotran on the chondrogenesis of human mesenchymal stem cells. Contrast Media Mol Imaging. 2009:4:165-73.

43. Schäfer R, Ayturan M, Bantleon R, Kehlbach R, Siegel G, Pintaske J, Conrad S, Wolburg $\mathrm{H}$, Northoff $\mathrm{H}$, Wiskirchen J, Weissert R. The use of clinically approved small particles of iron oxide (SPIO) for labeling of mesenchymal stem cells aggravates clinical symptoms in experimental autoimmune encephalomyelitis and influences their in vivo distribution. Cell Transplant. 2008;17:923-41.

44. Albuquerque WWC, Costa RMPB, de Salazar e Fernandes T, Porto ALF. Evidences of the static magnetic field influence on cellular systems. Prog Biophys Mol Biol. 2016;121:16-28.

45. Javani Jouni F, Abdolmaleki P, Movahedin M. Investigation on the effect of static magnetic field up to $15 \mathrm{mT}$ on the viability and proliferation rate of rat bone marrow stem cells. In Vitro Cell Dev Biol Anim. 2013;49:212-9.

46. Marędziak M, Marycz K, Smieszek A, Lewandowski D, Toker NY. The influence of static magnetic fields on canine and equine mesenchymal stem cells derived from adipose tissue. In Vitro Cell Dev Biol Anim. 2014;50:562-71.

47. Kim E-C, Leesungbok R, Lee S-W, Lee H-W, Park SH, Mah S-J, Ahn S-J. Effects of moderate intensity static magnetic fields on human bone marrowderived mesenchymal stem cells. Bioelectromagnetics. 2015;36:267-76.

48. Amin HD, Brady MA, St-Pierre J-P, Stevens MM, Overby DR, Ethier CR. Stimulation of chondrogenic differentiation of adult human bone marrowderived stromal cells by a moderate-strength static magnetic field. Tissue Eng Part A. 2014;20:1612-20.

49. Huang Z, Shen Y, Pei N, Sun A, Xu J, Song Y, Huang G, Sun X, Zhang S, Qin Q, Zhu H, Yang S, Yang X, Zou Y, Qian J, Ge J. The effect of nonuniform magnetic targeting of intracoronary-delivering mesenchymal stem cells on coronary embolisation. Biomaterials. 2013;34:9905-16.

50. Gao LR, Pei XT, Ding QA, Chen Y, Zhang NK, Chen HY, Wang ZG, Wang YF, Zhu ZM, Li TC, Liu HL, Tong ZC, Yang Y, Nan X, Guo F, Shen JL, Shen YH, Zhang JJ, Fei YX, Xu HT, Wang LH, Tian HT, Liu DQ, Yang Y. A critical challenge: dosage-related efficacy and acute complication intracoronary injection of autologous bone marrow mesenchymal stem cells in acute myocardial infarction. Int J Cardiol. 2013;168:3191-9. 